\title{
McKENZIE NECK EXERCISE LEBIH BAIK DALAM MENURUNKAN DISABILITAS LEHER DARIPADA DYNAMIC NECK EXERCISE PADA PENJAHIT DENGAN MYOFASCIAL PAIN SYNDROME OTOT UPPER TRAPEZIUS
}

\author{
Boki Jaleha $^{1}$, I Putu Gede Adiatmika ${ }^{2}$, Sugijanto ${ }^{3}$, I Made Muliarta ${ }^{2}$, Ketut \\ Tirtayasa $^{2}$, I Made Krisna Dinata \\ ${ }^{1}$ Program Studi Magister Fisiologi Keolahragaan Universitas Udayana, Denpasar \\ ${ }^{2}$ Departemen Ilmu Faal Fakultas Kedokteran Universitas Udayana, Denpasar \\ ${ }^{3}$ Fakultas Fisioterapi Universitas Esa Unggul, Jakarta
}

Email: bokiijaleha@gmail.com

\begin{abstract}
ABSTRAK
Pendahuluan: Myofascial pain syndrome otot upper trapezius merupakan gangguan muskuloskeletal pada otot upper trapezius akibat penggunaan otot secara berlebihan, postur yang jelek, dan repetitif mikrotrauma sehingga menyebabkan nyeri, taut band, kelemahan otot dan disabilitas pada daerah leher. Tujuan Penelitian: Untuk mengetahui perbedaan efek kedua intervensi, Mckenzie Neck Exercise dan Dynamic Neck Exercise dalam menurunkan disabilitas leher pada penjahit dengan myofascial pain syndrome otot upper trapezius. Metode: Penelitian eksperimental ini menggunakan rancangan randomized pre and post test two group design. Sampel penelitian sebanyak 18 orang yang dibagi secara acak menjadi 2 kelompok, masingmasing kelompok berjumlah 9 orang. Kelompok I diberikan McKenzie Neck Exercise sedangkan Kelompok II diberikan Dynamic Neck Exercise. Perlakuan dilakukan 3 kali seminggu selama 6 minggu dengan evaluasi menggunakan kuesioner penilaian Neck Disability Index (NDI). Hasil: Hasil uji statistik menggunakan paired-samples $t$ test pada Kelompok I dengan rerata skor sebelum intervensi $(23,8 \pm 2,1) \%$ dan sesudah intervensi yaitu $(16,4 \pm 2,4) \%$ dengan nilai $(p<0,05)$ dan Kelompok II dengan rerata skor sebelum intervensi $(23,6 \pm 2,2) \%$ dan sesudah intervensi $(20,9 \pm 2,3) \%$ dengan nilai $(p<0,05)$. Uji beda hipotesis antara Kelompok I dengan Kelompok II menggunakan independent-samples $t$ test diperoleh nilai $(\mathrm{p}<0,05)$. Simpulan: McKenzie Neck Exercise lebih baik dalam menurunkan disabilitas leher daripada Dynamic Neck Exercise dengan myofascial pain syndrome otot upper trapezius. Saran: Penelitian selanjutnya diharapkan dapat mengontrol aktivitas pekerja dilingkungan kerja maupun tempat tinggal dan diperlukan adanya tindak lanjut ataupun pengawasan (follow up) sampel penelitian setelah berakhirnya program penelitian pada masing-masing sampel, untuk mengetahui hasil intervensi yang diberikan dapat memberikan efek jangka panjang.
\end{abstract}

Kata Kunci: McKenzie Neck Exercise, Dynamic Neck Exercise, myofascial pain syndrome otot upper trapezius 


\title{
MCKENZIE NECK EXERCISE IS BETTER TO REDUCE NECK DISABILITY THAN DYNAMIC NECK EXERCISE ON TAILOR WITH MYOFASCIAL PAIN SYNDROME OF UPPER TRAPEZIUS MUSCLE
}

\begin{abstract}
Introduction: The myofascial pain syndrome of upper trapezius muscle is a musculoskeletal disorder in the upper trapezius caused by the overuse of muscle activity, bad posture and repetitive microtrauma resulting in the pain. The taut band, the muscle weakness, and disability on the neck region. Purpose: The purpose of this study is to know the different effect between McKenzie Neck Exercise and Dynamic Neck Exercise to reduce neck disability on tailor with myofascial pain syndrome of upper trapezius muscle. Method: This study was experimental with a pre-test and post-test of two groups design. All participants were 18 people divided into 2 groups with random alocation, each group was 9 people. Group I was given a McKenzie Neck Exercise while Group II was applied the Dynamic Neck Exercise. This study was conducted 3 times a week for 6 weeks by using the neck disability index (NDI) questionnaire. Result: The results of statistical tests using Paired-Samples $t$ Test in Group I showed mean before intervention were $(23.8 \pm 2.1) \%$ and after the intervention that was $(16.4 \pm 2.4) \%$ with a value of $(\mathrm{p}<0.05)$ and Group II showed mean before intervention $(23.6 \pm 2.2) \%$ and after intervention $(20.9 \pm 2.3) \%$ with a value of ( $\mathrm{p}<0.05)$. Different hypothesis test between Group I and Group II using IndependentSamples $t$ Test obtained ( $\mathrm{p}<0.05$ ). Conclusion: The conclusion of this study is McKenzie Neck Exercise is better to reduce neck disability than Dynamic Neck Exercise on tailor with myofascial pain syndrome of upper trapezius muscle. For the further research hopefully can controlling the activities of sample in the working place or home environment and research sample need to be follow-up after the last program in each Sample to find out the result of intervention that can given long-term effect.
\end{abstract}

Keyword: McKenzie Neck Exercise, Dynamic Neck Exercise, myofascial pain syndrome of upper trapezius muscle

\section{PENDAHULUAN}

Gangguan muskuloskeletal merupakan gangguan otot, tendon, ligamen, sendi dan tulang rawan juga sistem saraf yang mempengaruhi hampir semua bagian tubuh termasuk lengan, punggung, tangan, dan kaki. Jika dilakukan terus menerus serta berulangulang pada posisi tetap dan statis maka lebih rentan terkena masalah kesehatan ${ }^{1}$.

Myofascial pain syndrome (MPS)
merupakan salah satu gangguan
muskuloskeletal yang ditandai adanya trigger
point di area yang sensitif dalam taut band
otot skeletal, jika diberikan tekanan pada area
tersebut akan menimbulkan nyeri yang

spesifik pada suatu titik yang ditekan (tenderness). Trigger point yang aktif dan menimbulkan nyeri banyak dijumpai pada otot upper trapezius ${ }^{2}$.

Otot upper trapezius atau otot tonik (Tipe I) berfungsi untuk mempertahankan postur kepala yang cenderung ke depan karena kekuatan gravitasi dan berat kepala itu sendiri. Kerja otot ini akan semakin meningkat apabila otot mengalami trauma, degenerasi otot dan faktor mekanik yang meliputi poor body mechanics, penggunaan otot dalam posisi statis lama, kompresi pada otot dan mekanisme kerja yang buruk pada leher dan bahu. Akibatnya, otot akan sering menhalami spasme, pemendekan otot, 
tightness, penurunan sirkulasi darah yang akan menjadi pemicu timbulnya trigger points pada taut band sehingga dapat menyebabkan terjadinya myofascial pain syndrome otot upper trapezius ${ }^{3}$.

Prevalensi dari myofascial pain syndrome bervariasi pada populasi umum, lebih dari satu perkiraan melaporkan bahwa $24,1 \%$ wanita lebih banyak terkena myofascial pain syndrome dibandingkan pria hanya $23,8 \%{ }^{4}$. Tingkat kejadian myofascial pain syndrome di Amerika Serikat mencapai $85 \%$ hingga $90 \%$ dan titik nyeri $84 \%$ terjadi pada otot upper trapezius 5 .

Myofascial pain syndrome akan mengakibatkan terjadinya disabilitas pada leher berupa kekakuan, keterbatasan lingkup gerak sendi (LGS), dan penurunan fleksibilitas otot. Disabilitas leher yang dialami oleh para penjahit dibutuhkan latihan berupa penguatan otot-otot sekitar leher. Latihan penguatan otot yang dibutuhkan untuk menangani kondisi patologis atau untuk memperbaiki gangguan gerak dan fungsi. Oleh karena itu, intervensi yang diberikan harus sesuai agar dapat mempengaruhi keberhasilan suatu proses rangkaian penatalaksanaan Fisioterapi.

McKenzie Neck Exercise (MNE) merupakan latihan berupa penguluran spine dan otot yang dilakukan sepanjang gerakan latihan dengan repetisi yang telah ditentukan bertujuan untuk memperbaiki atau mengoreksi postur yang salah saat beraktivitas baik statis maupun dinamis, mengembalikan aligment leher yang normal, mengurangi kekakuan (stiffness) pada intervertebralis joints yang diakibatkan oleh spasme otot, dan memberikan efek muscle elongation 6 .

Dynamic Neck Exercise (DNE) merupakan latihan yang dilakukan secara aktif oleh individu/pasien meliputi ketahanan, misalnya isometrik. Latihan ini bertujuan untuk meningkatkan kekuatan otot karena dapat mengaktifkan berbagai reseptor seperti aferen, golgi tendon organ dan reseptor kulit. Peningkatan aliran dalam darah karena merespon latihan aktif yang dapat mengeluarkan dari sisa metabolisme sehingga terjadi peningkatan suhu otot dari energi yang dilepaskan selama latihan aktif dapat membuat nyeri otot lebih menurun ${ }^{7}$.

Pada penelitian ini penulis membandingkan McKenzie Neck Exercise dan Dynamic Neck Exercise dalam menurunkan disabilitas leher pada penjahit dengan myofascial pain syndrome otot upper trapezius. Ke dua latihan ini akan membantu meningkatkan kekuatan otot upper trapezius sehingga spasme serta kekakuan akan berkurang.

\section{METODE PENELITIAN}

Penelitian eksperimental ini menggunakan rancangan randomized pre and post test two group design. Kelompok I diberikan McKenzie Neck Exercise dan Kelompok II diberikan Dynamic Neck Exercise. Alat ukur pada penelitian ini menggunakan kuesioner penilaian Neck Disability Index (NDI).

Penelitian ini dilakukan di Industri Garmen Adhi Fashion Denpasar, pada bulan Maret April 2019. Sampel berjumlah 9 orang di masing-masing kelompok. Penelitian dilakukan dengan frekuensi 3 kali seminggu selama 6 minggu. Populasi target dalam penelitian ini adalah semua penjahit yang terindikasi myofascial pain syndrome otot upper trapezius dengan populasi terjangkau penjahit di Industri Garmen Adhi Fashion.

Adapun kriteria inklusi dalam penelitian ini adalah responden berusia 30 - 50 tahun, dengan skor NDI 10 - 14 (Ringan-Berat), adanya tightness, sample positif menderita nyeri akibat myofascial pain syndrome serta bersedia menjadi sampel dan menandatangani informed consent. Kriteria eksklusi pada penelitian ini adalah sampel dengan riwayat fraktur cervical, HNP cervical, spondilolisthesis cervical dan peradangan 
akut pada leher. Kriteria drop out dalam penelitian ini adalah sampel mengundurkan diri, sampel tidak mengikuti latihan yang telah terjadwal, dan sampel tiba-tiba jatuh sakit atau mengalami cedera karena suatu hal.

\section{HASIL PENELITIAN}

\section{Karakteristik Subjek Penelitian}

Data yang diambil berdasarkan kriteria subjek penelitian digambarkan pada Tabel 1 .

Tabel 1

Karakteristik Subjek

\begin{tabular}{llcccc}
\hline Karakteristik & Kategori & \multicolumn{2}{c}{ Frekuensi } & \multicolumn{2}{c}{ Persen (\%) } \\
\cline { 3 - 6 } & & Ke & Kel. & Kel. & Kel. \\
& & 1.1 & II & 1 & II \\
\hline Jenis & Laki-laki & 2 & 2 & 22,2 & 22,2 \\
Kelamin & Perempuan & 7 & 7 & 77,8 & 77,8 \\
Usia & $>45$ tahun & 4 & 4 & 44,4 & 44,4 \\
& $<45$ tahun & 5 & 5 & 55,6 & 55,6 \\
Posisi Kerja & Tegak & 2 & 1 & 22,2 & 11,1 \\
& Menunduk & 7 & 8 & 77,8 & 88,9 \\
\hline
\end{tabular}

Berdasarkan Tabel 1, Sampel penelitian terdiri dari jenis kelamin, usia, dan posisi kerja. Menunjukkan bahwa data karakteristik jenis kelamin dan usia untuk seluruh karakteristik sampel antara ke dua kelompok memiliki karakteristik yang sama.

\section{Uji Normalitas dan Uji Homogenitas}

Tabel 2

Uji Normalitas dan Uji Homogenitas

\begin{tabular}{|c|c|c|c|}
\hline & Kelompok I & Kelompok II & \multirow{3}{*}{$\begin{array}{c}p \text {-value } \\
\text { (Levene's } \\
\text { Test) }\end{array}$} \\
\hline & \multicolumn{2}{|c|}{ Shapiro Wilk Test } & \\
\hline & $p$-value & p-value & \\
\hline $\begin{array}{l}\text { Sebelum } \\
\text { Intervensi }\end{array}$ & 0,194 & 0,172 & 0,712 \\
\hline $\begin{array}{c}\text { Sesudah } \\
\text { Intervensi }\end{array}$ & 0,076 & 0,248 & \\
\hline
\end{tabular}

Berdasarkan Tabel 2, data menunjukkan bahwa hasil uji normalitas berdistribusi normal pada ke dua kelompok dengan nilai $p$
$>0,05$. Hasil uji homogenitas memiliki data yang homogen pada ke dua kelompok sebelum intervensi dengan nilai $p>0,05$.

\section{Uji Perbandingan Rerata Skor Disabilitas Leher Myofascial Pain Syndrome Otot Upper Trapezius}

Tabel 3

Hasil Uji Perbandingan Rerata Skor Disabilitas Leher

\begin{tabular}{|c|c|c|c|c|c|c|}
\hline \multirow{2}{*}{$\mathrm{KP}$} & \multirow{2}{*}{$\begin{array}{c}\text { Pre Test } \\
\text { Rerata } \pm \\
\text { SB }\end{array}$} & \multirow{2}{*}{$\begin{array}{c}\text { Post Test } \\
\text { Rerata } \pm \\
\text { SB }\end{array}$} & \multirow{2}{*}{$\begin{array}{c}\text { Selisih } \\
\begin{array}{c}\text { Rerata } \\
\pm \mathrm{SB}\end{array}\end{array}$} & \multicolumn{2}{|c|}{$95 \% \mathrm{CI}$} & \multirow[b]{2}{*}{$p^{*}$} \\
\hline & & & & Lower & Upper & \\
\hline I & $23,8 \pm 2,1$ & $\begin{array}{c}16,4 \pm \\
2,4\end{array}$ & $\begin{array}{c}7,3 \pm \\
1,0\end{array}$ & 6,564 & 8,102 & 0,001 \\
\hline II & $23,6 \pm 2,2$ & $\begin{array}{c}20,9 \pm \\
2,3\end{array}$ & $\begin{array}{c}2,7 \pm \\
1,4\end{array}$ & 1,579 & 3,753 & 0,001 \\
\hline$p^{* *}$ & 0,829 & 0,001 & 0,001 & & & \\
\hline
\end{tabular}

Berdasarkan Tabel 3, hasil uji hipotesis I dengan paired-samples $t$ test didapatkan nilai $(p<0,05)$ sehingga disimpulkan bahwa McKenzie Neck Exercise dapat menurunkan disabilitas leher dengan myofascial pain syndrome otot upper trapezius. Pada uji hipotesis II dengan paired-samples $t$ test didapatkan nilai $(p<0,05)$ sehingga disimpulkan bahwa Dynamic Neck Exercise dapat menurunkan disabilitas leher dengan myofascial pain syndrome otot upper trapezius. Uji hipotesis III menggunakan independent-samples $t$ test didapatkan hasil skor disabilitas leher berbeda sesudah intervensi dengan nilai $p 0,001(p<0,05)$ hal ini menunjukkan ada perbedaan yang signifikan pada Kelompok I dan Kelompok II. Selisih penurunan pada Kelompok I lebih besar $(7,3 \pm 1,0) \%$ daripada selisih penurunan pada Kelompok II $(2,7 \pm 1,4) \%$.

\section{PEMBAHASAN}

Pemberian Intervensi McKenzie Neck Exercise dapat menyebabkan terjadinya perbaikan pada diskus dan akan mendorong diskus intervertebralis masuk ke dalam sehingga penekanan terhadap akar saraf berkurang dan nyeri pun akan berkurang. 
Pengurangan nyeri dimulai dari bagian distal menuju proximal dan akhirnya terpusat di leher, pemusatan nyeri ini dikenal sebagai centralization phenomenon ${ }^{8}$ Teknik McKenzie Neck Exercise menargetkan deformitas mekanik dan keterbatasan, sehingga pasien akan merasakan peningkatan kemampuan fungsionalnya dengan sangat baik.

Pemberian Intervensi McKenzie Neck Exercise dapat mengurangi nyeri pada pasien dengan nyeri tengkuk. Terjadinya penurunan nyeri disebabkan karena pemberian latihan McKenzie dapat memberikan efek relaksasi pada otot setelah kontraksi maksimal sehingga menimbulkan efek inhibisi pada otot yang spasme ${ }^{9}$. McKenzie Neck Exercise dapat menghasilkan efek mekanik pada otot sehingga lambat laun terjadi penurunan ketegangan otot akibat aktivitas dan jaringan ikat lainnya yang ada di sekitar lumbal mudah terulur. Dengan demikian dapat disimpulkan bahwa pemberian McKenzie Neck Exercise dapat menurunkan nyeri pada pasien dengan keluhan nyeri leher.

Kondisi myofascial pain syndrome menyebabkan terjadinya penurunan kekuatan otot karena nyeri yang membatasi. Peningkatan kekuatan otot regio cervical dapat terjadi dengan dilakukannya McKenzie Neck Exercise yang banyak menggunakan gerakan aktif yang diulang sehingga memungkinkan terjadinya peningkatan kekuatan otot. peningkatan kekuatan otot karena suatu gerakan pada tubuh selalu diikuti kontraksi otot, kontraksi otot tergantung dari banyaknya motor unit yang terpasang. Hasilnya kekuatan otot dan daya tahan otot pun meningkat ${ }^{9}$. McKenzie Neck Exercise dilakukan sebanyak 10 repetisi. Latihan ini dilakukan selama 3 kali seminggu dalam rentang waktu selama 6 minggu.

Dynamic Neck Exercise adalah latihan penguatan yang dilakukan secara aktif oleh individu/pasien meliputi ketahanan, misalnya isometrik $^{10}$. Latihan isometrik adalah satu bentuk latihan strengthening yang dilakukan pada saat otot berkontraksi tanpa terjadi perubahan panjang otot dan tanpa adanya gerakan sendi ${ }^{11}$. Latihan Isometrik dapat memicu reaksi pada golgi tendon organ pada otot. Impuls saraf afferent dari golgi tendon masuk ke bagian dorsal spinal cord dan bertemu dengan inhibitor motor neuron, hal ini yang menyebabkan terputusnya impuls motor neuron efferent dan menyebabkan relaksasi pada otot.

Dynamic Neck Exercise adalah latihan yang bertujuan untuk penguatan otot. Salah satu latihan stabilisasi adalah dengan menggunakan latihan isometrik. Pada latihan ini terjadi kontraksi submaksimal pada otot yang mampu meningkatkan stabilitas postural atau stabilitas dinamis pada sendi menggunakan kontraksi isometrik pada lingkup gerak middle range ${ }^{12}$.

Kontraksi isomterik otot yang kuat akan mempengaruhi mekanisme pumping action sehingga proses metabolisme dan sirkulasi lokal dapat berlangsung dengan baik sebagai akibat dari vasodilatasi dan relaksasi setelah kontraksi maksimal dari otot tersebut. Dengan demikian maka pengangkutan zat sisa-sisa metabolisme ( $p$ subtance) melalui proses inflamasi dapat berjalan dengan lancar sehingga rasa nyeri dapat berkurang ${ }^{13}$.

Diberikannya Dynamic Exercise akan terjadi peningkatan gerakan sendi yang menghasilkan fleksibilitas kapsul, ligamen, dan otot serta peningkatan nutrisi tulang rawan. Penguatan otot terjadi pada semua rentang sendi yang dicapai selama latihan dan menghasilkan kompleks sendi otot yang secara fungsional lebih efisien ${ }^{14}$.

Dynamic Neck Exercise juga merupakan metode yang efektif untuk mengurangi nyeri yang dapat mengakibatkan keterbatasan gerak di sekitar leher. Dynamic Neck Exercise dilakukan sebanyak 3 set dengan 10 repetisi. Latihan ini dilakukan selama 3 kali seminggu dalam rentang waktu selama 6 minggu. 


\section{SIMPULAN}

1. Pemberian McKenzie Neck Exercise dapat menurunkan disabilitas leher pada penjahit dengan myofascial pain syndrome otot upper trapezius.

2. Pemberian Dynamic Neck Exercise dapat menurunkan disabilitas leher pada penjahit dengan myofascial pain syndrome otot upper trapezius.

3. Pemberian McKenzie Neck Exercise lebih baik dalam menurunkan disabilitas leher daripada Dynamic Neck Exercise pada penjahit dengan myofascial pain syndrome otot upper trapezius.

\section{SARAN}

Penelitian selanjutnya diharapkan dapat mengontrol aktivitas pekerja di lingkungan kerja maupun tempat tinggal dan diperlukan adanya tindak lanjut ataupun pengawasan (follow up) sampel penelitian setelah berakhirnya program penelitian pada masingmasing sampel, untuk mengetahui hasil intervensi yang diberikan dapat memberikan efek jangka panjang.

\section{DAFTAR PUSTAKA}

1. Chandra, N dan Dubey, N. 2014. Role of Rest Period: An Ergonomic Study on Sewing Machine Operators. Research journal of Family, Community and Consumer Sciences. Vol 2 (7), 12-14 Auguts 2014. India

2. Bennet, R. 2007. Myofascial Pain Syndromes and Their Evaluation. Best Practice and Research in Clinical Rheumatology, 21(3):427-445

3. Widodo, A. 2011. "Penambahan Ischemic Pressure, Sustained Stretching, dan Koreksi Posture bermanfaat pada intevensi kasus myofascial trigger point syndrome otot trapezius bagian atas" (Thesis). Denpasar: Universitas Udayana
4. Borg-Stein J, Iaccarino MA. 2014. Myofascial Pain Syndrome Treatments. Phys Med Rehabil Clin N Am. 25(2): 357-374.

5. Makmuriyah dan Sugijanto. 2013. Iontophoresis Diclofenac Lebih Efektif Dibandingkan Ultrasound Terhadap Pengurangan Nyeri Pada Myofascial Syndrome Musculus Upper Trapezius. Jurnal Fisioterapi Esa Unggul Vol 13 No 1, April 2013

6. Kage, V., Patel, NY., Pai, MP. 2016. To Compare The Effects Of Deep Neck Flexors Strenghtening Exercise And Mckenzie Neck Exercise In Subjects With Forward Neck Posture: A Randomised Clinical Trial. India : Karnataka.

7. Kaka, B. Omoyemi, O. Oyumiik Samuel, O, Ogunlade dan Ade, F. Adeniyi. 2015. Effects of neck stabilization and dynamic exercises on pain, disability and fear avoidance beliefs in patients with non specific neck pain; a randomized clinical trial. Bayero University, P.M.B 3011. Kano. Nigeria.

8. Dutton, M. 2002. Manual Therapy of The Spine, An Integrated Approach. New York: Mcgrow-Hill Companies

9. Cameron, M. H. 2009. Physical Agents in Rehabilitation From Research to Practice. Sounders Elsevier. Portland

10. Ganong, W.F. 2008. Buku Ajar Fisiologi Kedokteran. Jakarta: EGC.

11. Delyuzir, N. Y dan Lesmana, S. I. 2009. "Perbedaaan Pengaruh Pemberian MWD. US, Latihan Eksentrik Quadriceps dengan MWD, US, Latihan Statik Isometrik Quadriceps terhadap Peningkatan Kekuatan Otot Quadriceps pada Tendinitis Patelaris" (Skripsi). Jakarta: Universitas Esa Unggul.

12. Kisner, C. dan Colby, L.A. 2012. Therapeutic Exercise Foundations And 
Techniques: SixthEdition. Philadelphia: F. A. Davis Company

13. Guyton, A. C dan Hall, J. E. 2008. Textbook of medical physiology, 11th Edition. Philadelphia: Elsevier Saunder.
14. Kamalakannan dan Kalyani. 2018. Effecttiveness of dynamic neck exercise along with interferential therapy in patients with chronic mechanical pain. International journal of academic resesrch and development. Vol 3 (2). 927-932. 